\title{
A role for skeletal muscle stearoyl-CoA desaturase 1 in control of thermogenesis
}

\author{
Davide Mainieri,* Serge Summermatter,* Josiane Seydoux,* Jean-Pierre Montani,* \\ Sandro Rusconi, ${ }^{\dagger}$ Aaron P. Russell, ${ }^{\ddagger}$ Olivier Boss, ${ }^{\S}$ Antony J. Buchala, ${ }^{\|}$and \\ Abdul G. Dulloo*,1 \\ Division of *Physiology and ${ }^{\dagger}$ Biochemistry, Department of Medicine, Faculty of Science, University \\ of Fribourg, Fribourg, Switzerland; ${ }^{\ddagger}$ Clinique de réadaptation, SUVA Care, Sion, Switzerland; \\ ${ }^{\S}$ Endocrinology of Energy Metabolism, Boston, Massachusetts, USA; and "Department of Biology, \\ Faculty of Science, University of Fribourg, Fribourg, Switzerland
}

ABSTRACT An enhanced metabolic efficiency for accelerating the recovery of fat mass (or catch-up fat) is a characteristic feature of body weight regulation after weight loss or growth retardation and is the outcome of an "adipose-specific" suppression of thermogenesis, i.e., a feedback control system in which signals from the depleted adipose tissue fat stores exert a suppressive effect on thermogenesis. Using a previously described rat model of semistarvation-refeeding in which catch-up fat results from suppressed thermogenesis per se, we report here that the gene expression of stearoyl-coenzyme A desaturase 1 (SCD1) is elevated in skeletal muscle after 2 wk of semistarvation and remains elevated in parallel to the phase of suppressed thermogenesis favoring catch-up fat during refeeding. These elevations in the SCD1 transcript are skeletal muscle specific and are associated with elevations in microsomal $\Delta 9$ desaturase enzyme activity, in the $\Delta 9$ desaturation index, and in the relative content of SCD1-derived monounsaturates in several lipid fractions extracted from skeletal muscle. An elevated skeletal muscle SCD1, by desaturating the products of de novo lipogenesis and diverting them away from mitochondrial oxidation, would inhibit substrate cycling between de novo lipogenesis and lipid oxidation, thereby leading to a state of suppressed thermogenesis that regulates the body's fat stores.-Mainieri, D., Summermatter, S., Seydoux, J., Montani, J. P., Rusconi, S., Russell, A. P., Boss, O., Buchala, A. J., Dulloo, A. G. A role for skeletal muscle stearoyl-CoA desaturase 1 in control of thermogenesis. FASEB J. 20, E1157-E1170 (2006)

Key Words: obesity $\cdot$ weight cycling $\cdot$ catch-up growth $\cdot$ low birth weight $\cdot$ insulin resistance

THE ABILITY of mammals to adapt to diminished food intake by increasing the efficiency of energy utilization has been well documented from studies of prolonged starvation in humans (1-3) and laboratory rodents (4). This capacity for energy conservation is viewed as the outcome of regulatory processes that, in response to the deficit in energy intake, suppress thermogenesis and hence slow the rate of weight loss and reduce the energy cost for weight maintenance. Since processes that enhance metabolic efficiency by suppressing thermogenesis also occur during refeeding (5-9), with the energy spared being directed specifically at accelerating the recovery of body fat $(2,10)$, i.e., for preferential catch-up fat, it is also viewed as the outcome of a control system that operates as a feedback loop between the size of the adipose fat stores and thermogenesis. This has been referred to as "adipose-specific" control of thermogenesis, i.e., an autoregulatory feedback system in which signal(s) from the depleted adipose fat stores exert a suppressive effect on thermogenesis until the fat stores are replenished (11). Such an energy conservation mechanism, which probably evolved to optimize survival capacity in an ancestral lifestyle characterized by periodic food shortage, is an important factor that nowadays contributes to the relapse of obesity after slimming and hence to the poor efficacy of dietary restriction in the management of obesity. It also contributes to preferential catch-up fat associated with insulin resistance during catch-up growth after earlier malnutrition $(12,13)$, and it has been implicated in the link between earlier growth retardation, catch-up growth, and increased risks for type 2 diabetes and cardiovascular disease later in life (14).

At present, our understanding of the components that constitute this adipose-specific control of thermogenesis, i.e., its sensors, signals, and effector system, is fragmentary. The demonstration in the rat that the suppression of thermogenesis directed at catch-up fat persists unabated during exposure to cold (15), i.e., under conditions of enhanced sympathetically mediated thermogenesis (16), has suggested that its effector mechanisms might be dissociated from diminished activity of the sympathetic nervous system (SNS) and by extension from sympathetic modulation of the uncoupling protein (UCP) in brown adipose tissue (UCP1).

\footnotetext{
${ }^{1}$ Correspondence: Division of Physiology, Department of Medicine, University of Fribourg, Chemin du Musée 5, CH-1700 Fribourg, Switzerland. E-mail: abdul.dulloo@unifr.ch doi: 10.1096/fj.06-5934fje
} 
In contrast, because SNS activity in skeletal muscle is mostly unresponsive to modulation by diet or to cold exposure (17) and this tissue is a major site for energy conservation during prolonged starvation (18), skeletal muscle is thought to be the major effector site for this (SNS-independent) adipose-specific control of thermogenesis (11). However, despite the fact that skeletal muscle, which accounts for $30-40 \%$ of body mass in mammals, has long been considered as a major site for adaptive thermogenesis, the underlying effector mechanisms remain elusive. Earlier interest that such regulated thermogenesis in skeletal muscle might involve mitochondrial uncoupling by UCP2 or UCP3 (two homologues of UCP1) has waned after the demonstrations that they are either up-regulated or unaltered in response to starvation and refeeding (19-22), a pattern of expression inconsistent with a role for these UCP homologues in the control of adaptive thermogenesis.

Within the context of this feedback loop between the fat stores and skeletal muscle, we have conducted studies aimed at gaining insights into the molecularphysiological mechanisms that could constitute the effector system that suppress thermogenesis in skeletal muscle for the purpose of catch-up fat. To this end, we have used a previously described rat model of semistarvation-refeeding $(10-12)$ in an attempt to identify and validate genes the altered expression of which in skeletal muscle during semistarvation would persist during refeeding in parallel to the enhanced efficiency for catch-up fat and to investigate the underlying neurohormonal systems. The results reported here suggest that skeletal muscle stearoyl-coenzyme A desaturase 1 (SCD1), a rate-limiting enzyme that catalyzes the synthesis of monounsaturated fatty acids (MUFA), is a key control point in the neurohormonal effector system of the adipose-specific control of thermogenesis.

\section{MATERIALS AND METHODS}

\section{Animals and diets}

Male Sprague-Dawley rats (Elevage Janvier, France), aged 6 wk and caged singly in a temperature-controlled room $\left(22 \pm 1^{\circ} \mathrm{C}\right)$ with a 12 -h light/dark cycle, were maintained on a commercial pelleted chow diet (Kliba, Cossonay, Switzerland) and had free access to tap water. The experiments were conducted after a 5 day period of adaptation in rats selected on the basis of body weight being within $\pm 5 \mathrm{~g}$ of the mean body weight $(215 \mathrm{~g})$. Animals used in the present studies were maintained in accordance with our institute's regulations and guide for the care and use of laboratory animals.

\section{Study design}

\section{Animal model}

The experiments were conducted by using a design similar to that previously described in establishing a rat model for studying changes in energy expenditure that occur specifically for accelerating fat deposition during refeeding (1012), i.e., an approach that allows suppressed thermogenesis specific for fat recovery to be studied in the absence of confounding variables, such as body size, food intake, and differential rates of protein gain, on energy expenditure. As shown in Fig. 1, groups of rats are food restricted at $50 \%$ of their spontaneous food intake for $2 \mathrm{wk}$. After this period of semistarvation, they are refed the same chow diet at a level equal in metabolizable energy content to the spontaneous food intake of control rats matched for weight at the onset of refeeding. The cardinal feature of this experimental design is that comparisons are made between refed animals regaining weight vs. spontaneously growing weight-matched controls, with both groups consuming the same amount of food energy. Under these conditions, the refed animals show an increased rate of body fat gain, which results from their lower energy expenditure, than in controls. A number of factors that could theoretically contribute to this difference in ener-
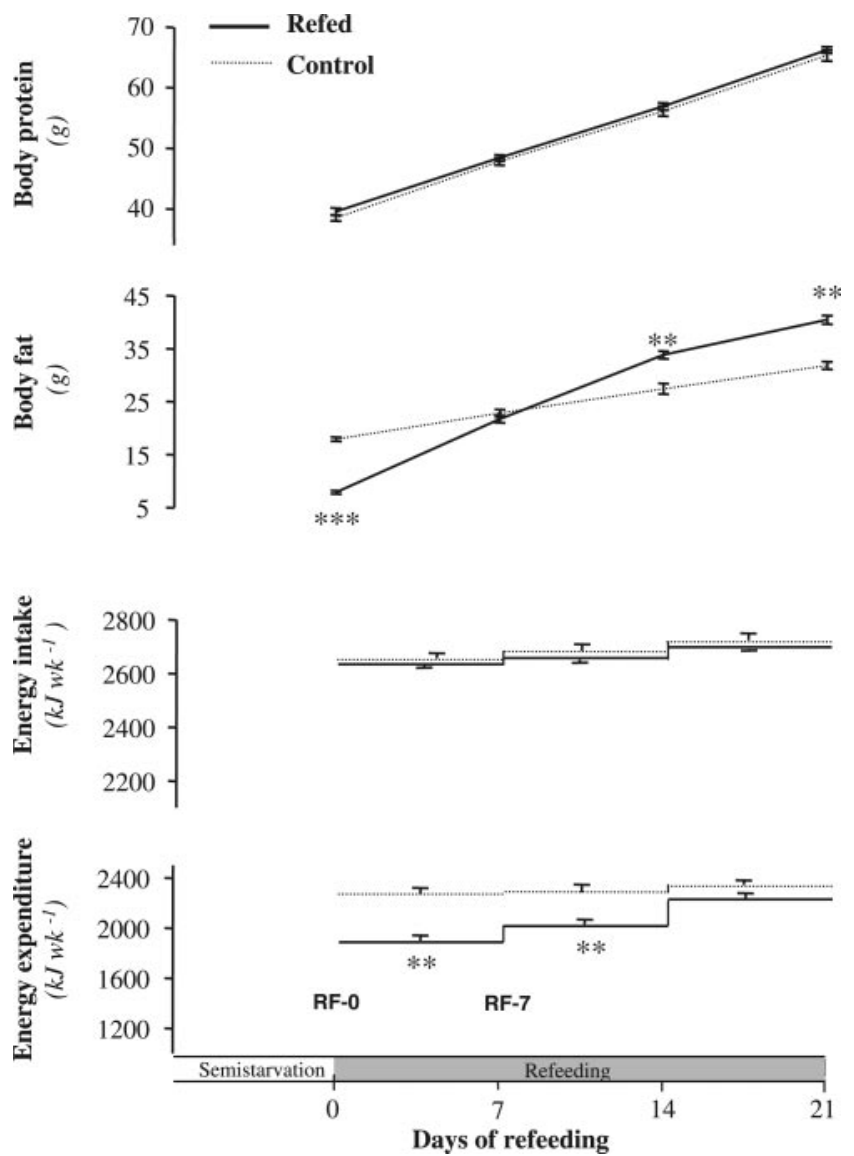

Figure 1. Study design for screening and validating candidate skeletal muscle genes implicated in adipose-specific suppression of thermogenesis using a previously described rat model of semistarvation-refeeding in which the accelerated fat recovery (catch-up fat) results only from suppressed thermogenesis, i.e., not from confounding effects of hyperphagia or lower lean body mass or protein mass $(10-12)$. In this study, energy balance and body composition measurements were determined over 3 successive periods of 1 wk each during course of refeeding and comparisons made with controls matched for weight at onset of refeeding. Acceleration of fat deposition but not that of protein deposition (i.e., preferential catch-up fat) is attributed to diminished energy expenditure (suppressed thermogenesis) that lasts for $\approx 2 \mathrm{wk}$. Skeletal muscle was harvested, namely at end of $2 \mathrm{wk}$ semistarvation period, i.e., at onset of refeeding (RF-0) and after 1 wk of refeeding (RF-7). All values are means and SE. $(n=6) ; * * P<$ $0.01 ; * * * P<0.001$. 
getics between refed and control rats (namely level of physical activity, age, and size of organs) have been previously evaluated $(4,10-12)$ and were shown to have little or no impact on the difference in energy expenditure between the two groups. Consequently, under the conditions of our refeeding studies, the lower energy expenditure in the refed than in control rats is explained by the energy spared as a result of a sustained suppression of thermogenesis for the purpose of catch-up fat.

\section{Gene search}

With the use of this rat model of catch-up fat caused by suppressed thermogenesis per se, two approaches were undertaken in the search for genes that could be implicated in the effector system of the adipose-specific suppression of thermogenesis: 1) by applying the technique of differential display followed by microarray analysis and 2) by screening a number of "literature" candidate genes implicated in thermogenesis and that are expressed in skeletal muscle; these are listed in Table 1, under "calcium cycling genes" $(23,24)$ and under "candidate genes by gene manipulation technology" (25-33), respectively. A critical feature of both these approaches was to identify skeletal muscle genes the altered mRNA expression of which at the end of the 2 wk semistarvation period (RF-0) would persist in the same direction after $1 \mathrm{wk}$ of controlled refeeding (RF-7), i.e., at a time point when thermogenesis is suppressed but also when body fat in the refed animals has not yet exceeded that in controls (Fig. 1). In other words, this search aimed at identifying genes that were either downregulated both at RF-0 and at RF-7 or up-regulated both at RF-0 and RF-7 and the altered expression of which during refeeding preceeded the appearance of excess adiposity and is hence not consequential to excess fat.

\section{Differential display}

mRNA differential display was performed using the protocol described by Brenz Verca et al. (34). Total cellular RNA was isolated from rat hind-limb skeletal muscle at time points RF-0 and RF-7 ( $n=6$ per group) using guanidine isothiocyanate extraction (35). Fifty micrograms of total RNA were then treated with $20 \mathrm{U}$ of RNase free-DNase (Life Technologies). Subsequently, $0.2 \mu \mathrm{g}$ of treated RNA were used in a reverse transcription reaction using each of the four 1-bp-anchored 3'oligo(dT) primers (DPLN) and $200 \mathrm{U}$ of Mo-MLV reverse transcriptase (Promega) in $20 \mu \mathrm{l}$ volume as recommended by the manufacturer. Two microliters of the reverse transcribed cDNA were then used for each polymerase chain reaction (PCR), which was performed using the same 1-bp-anchored 3 'oligo(dT) primer and $5^{\prime}$ arbitrary oligos (XAp); the sequences of primers used are provided in Table 1. The $50 \mu \mathrm{l}$ PCR reaction contained $10 \mathrm{mM}$ Tris- $\mathrm{HCl}$ at $\mathrm{pH} 8.3,50 \mathrm{mM}$ $\mathrm{KCl}, 1.5 \mathrm{mM} \mathrm{MgCl}, 0.01 \%$ gelatin, $2 \mu \mathrm{M}$ dNTP (except dATP), $1 \mu \mathrm{l}$ of $\alpha \mathrm{P}^{32}-\mathrm{dATP}(3000 \mathrm{Ci} / \mathrm{mmol}), 2 \mu \mathrm{M}$ of $5^{\prime}$ arbitrary oligo and $3^{\prime}$ anchored dT oligo, and $0.2 \mu$ l of Taq polymerase. Parameters for PCR were as follows: 5 cycles of denaturing at $95^{\circ} \mathrm{C}$ for $45 \mathrm{~s}$, annealing at $40^{\circ} \mathrm{C}$ for $1 \mathrm{~min}$, and extension at $72^{\circ} \mathrm{C}$ for $1 \mathrm{~min}$, then 35 cycles of denaturing at $95^{\circ} \mathrm{C}$ for $1 \mathrm{~min}$, annealing at $62^{\circ} \mathrm{C}$ for $1 \mathrm{~min}$, and extension at $72^{\circ} \mathrm{C}$ for $1 \mathrm{~min}$. Two microliters of the PCR reaction mixture were loaded on a $6 \%$ sequencing gel, and differentially amplified PCR fragments were visualized by exposing the dried sequencing gel to X-ray film. Candidate PCR products that satisfied the criteria in this step of our gene search, i.e., either up-regulated or down-regulated at both RF-0 and RF-7, were then excised from the sequencing gel, and the DNA was eluted by boiling the gel slice in TE buffer $(10 \mathrm{mM}$ Tris, $\mathrm{pH}$ 7.5 , and $1 \mathrm{mM}$ EDTA) for $10 \mathrm{~min}$. The eluted DNA fragment was reamplified by using the BT7 and XSP6 and subsequently cloned into the TA cloning vector (Invitrogen). Five transformants for each clone were sequenced (Rexagene), and the analysis of these data revealed 86 transcribed sequence. After cDNA microarray analysis (Memorec), the mRNA levels of genes of interest (selected on the basis of a change in mRNA level $>25 \%$ at both $\mathrm{RF}-0$ and RF-7 relative to respective control) were subsequently analyzed by real-time PCR.

\section{Semiquantitative real time-PCR}

Target cDNA levels were analyzed by semiquantitative real time (Q-RT)-PCR reaction in a buffer containing $10 \mathrm{mM}$ Tris-HCl pH 8.4, $25 \mathrm{mM} \mathrm{KCl,} 0.1 \mathrm{mM}$ each dNTP, $0.025 \mathrm{U}$ iTaq, $1.5 \mathrm{mM} \mathrm{MgCl}_{2}$, SYBR Green I, and $5 \mathrm{nM}$ fluorescein (iQ SYBR Green Supermix Bio-Rad). All the genes were amplified under the same conditions: 3 min $95^{\circ}$ for 1 cycle, $10 \mathrm{~s} 95^{\circ}$ and $45 \mathrm{~s} 62^{\circ}$ for 40 cycles, $1 \times 1 \mathrm{~min} 95^{\circ}$, and $1 \mathrm{~min} 55^{\circ}$ for $1 \mathrm{cycle}$, after which a melting curve was obtained $(80 \times 0.5$ degrees increments, $10 \mathrm{~s}$, from $\left.55-95^{\circ} \mathrm{C}\right)$. The cDNA reactions were diluted five times, and $4 \mu \mathrm{l}$ were used for the Q-RT-PCR. Q-RT-PCR was used to measure the mRNA levels of genes selected from differential display/microarray analysis and the literature candidate genes; the sequences of primers used are provided in Table 1 . All the cDNA were normalized against cyclophilin, a housekeeping gene the expression of which did not alter under our experimental conditions.

\section{Preparation of microsomal fractions and assay of $\Delta 9$ desaturase activity (SCD)}

The extraction of microsomes from skeletal muscle and subsequent assay for microsomal SCD activity were performed according the method described by Houdali et al. (36). Aliquots of excised muscles were weighed $(\approx 200 \mathrm{mg})$ and ground in a liquid nitrogen-cooled porcelain mortar, and powdered muscles were suspended in $1 \mathrm{ml}$ ice-cold buffer containing $10 \mathrm{mmol} / \mathrm{l}$ Tris, $\mathrm{pH} 7.4,1 \mathrm{mmol} / \mathrm{l}$ dithiothreitol and $0.25 \mathrm{~mol} / 1$ sucrose. Further homogenization was done with a motor-driven Potter-Elvehjem Teflon-glass tissue grinder at a setting $1500 \mathrm{rpm}$ and for $\approx 10$ cycles. Crude muscle homogenate was then spun at $15,000 \mathrm{~g}$ for $20 \mathrm{~min}$, after which the supernatant was spun in an ultracentrifuge at $100,000 \mathrm{~g}$ for $1 \mathrm{~h}$ at $4^{\circ} \mathrm{C}$. After the remaining supernatant was discarded, the microsomal fraction was resuspended in $200 \mu \mathrm{l}$ of $0.1 \mathrm{~mol} / 1$ sodium phosphate buffer, $\mathrm{pH} 7.4$; all steps were carried out at $4^{\circ} \mathrm{C}$. The protein concentration was then measured using the dye-based Bradford assay (Bio-Rad-Kit) and $\Delta 9$ desaturase (SCD) activity was measured in the microsomal fraction $(100 \mu \mathrm{l})$ by the generation of ${ }^{3} \mathrm{H}_{2} \mathrm{O}$ from the substrate $\left[9,10-{ }^{3} \mathrm{H}\right]$ stearoyl-coenzyme A (CoA; Biotrend Chemicals, Cologne, Germany, specific activity: $2.2 \times 1012$ $\mathrm{TBq} / \mathrm{mmol}$ ). Samples were incubated at $37^{\circ} \mathrm{C}$ for $5 \mathrm{~min}$, and the incubation was terminated by the addition of $1.3 \mathrm{ml}$ of ethanol and spun at 15,000 $\mathrm{g}$ for $5 \mathrm{~min}$. Residual substrate was removed by the addition of $40 \mathrm{mg}$ of Norit A, followed by centrifugation as before, and the ${ }^{3} \mathrm{H}_{2} \mathrm{O}$ produced was measured in the supernatant by liquid scintillation counting.

\section{Fatty acid composition analysis and $\Delta 9$ desaturation index}

Samples of $200 \mathrm{mg}$ skeletal muscle were suspended in $3.8 \mathrm{ml}$ of a mixture of chloroform:methanol:water (1:2:0.8, vol./ vol.), vortexed, and left to stand for $10 \mathrm{~min}$ at room temperature. Lipids were extracted, using the method of Bligh and Dyer (37), by vortexing with $1 \mathrm{ml}$ of chloroform and $1 \mathrm{ml}$ water, which resulted in a mixture of chloroform-methanolwater $(2: 2: 1.8$, vol.). After centrifugation for $5 \mathrm{~min}$ at 4000 
TABLE 1. Candidate genes screened by RT-PCR, and primers utilized

\begin{tabular}{|c|c|c|}
\hline Category/Gene Name & Function & Primers \\
\hline \multicolumn{3}{|l|}{$\begin{array}{l}\text { Candidate Genes } \\
\text { from Differential } \\
\text { Display }\end{array}$} \\
\hline MLC2 & $\begin{array}{l}\text { Isoform of the component of thick filament; } \\
\text { potentiates actin-myosin interaction at low } \mathrm{Ca}^{2+} \\
\text { levels }\end{array}$ & $\begin{array}{l}\text { Sense 5' ATCTCTGGAGCCTTCAAGGTC 3' } \\
\text { Antisense 5' ACATCTGGAGGGAAGGCTGC 3' }\end{array}$ \\
\hline MLC1/3 & $\begin{array}{l}\text { Isoform of the component of thick filament; } \\
\text { potentiates actin-myosin interaction at low } \mathrm{Ca}^{2+} \\
\text { levels }\end{array}$ & $\begin{array}{l}\text { Sense } 5^{\prime} \text { TGAACCGTCCAATCCAGCCG 3' } \\
\text { Anti-sense } 5^{\prime} \text { TGGAAGAGCAGTGGTGGCTC 3' }\end{array}$ \\
\hline MHC IIX/D & $\begin{array}{l}\text { Isoform of the component of thick filament; } \\
\text { present in the fast fibers }\end{array}$ & $\begin{array}{l}\text { Sense 5' TACTTACCAGACAGAAGAAGACG 3' } \\
\text { Anti-sense 5' AGCTCATGCTGCAGCTTGCG 3' }\end{array}$ \\
\hline MHC IIB & $\begin{array}{l}\text { Isoform of the component of thick filament; } \\
\text { present in the fast fibers }\end{array}$ & $\begin{array}{l}\text { Sense } 5^{\prime} \text { ACCGCAAGAACGTTCTCAGGC } 3^{\prime} \\
\text { Anti-sense } 5^{\prime} \text { TGCGGAACTTGGCCAGGTTG } 3^{\prime}\end{array}$ \\
\hline Troponin $\mathrm{C}$ & $\begin{array}{l}\text { Member of the troponin complex; present in slow } \\
\text { and fast fibers }\end{array}$ & $\begin{array}{l}\text { Sense } 5^{\prime} \text { TAAGAACAACGATGGCGGCATTGAC } 3^{\prime} \\
\text { Anti-sense } 5^{\prime} \text { GGACCTGCAGTCTGGATGAACACG } 3^{\prime}\end{array}$ \\
\hline Actin $\beta$ & Cytoskeletal house keeping gene & $\begin{array}{l}\text { Sense } 5^{\prime} \text { AGCGTGGCTACACGTTCACCAC 5' } \\
\text { Anti-sense } 5^{\prime} \text { AGTGATGACCTGACCGTCAGGC } 3^{\prime}\end{array}$ \\
\hline ColA1 & A member of group I collagen & $\begin{array}{l}\text { Sense } 5^{\prime} \text { TAGCCACAGCTGACACAAGACC } 3^{\prime} \\
\text { Anti-sense } 5^{\prime} \text { AAGCTGTGGCCTGGGTCTTCTTG } 3^{\prime}\end{array}$ \\
\hline MEG3/GTL2 & Imprinted untranslated gene & $\begin{array}{l}\text { Sense 5' AGGACTCCACATCGTTACGTTGC 3' } \\
\text { Anti-sense 5' ATTTACAGTTGGAAGGTCCTATGGG 3' }\end{array}$ \\
\hline \multicolumn{3}{|l|}{$\begin{array}{l}\text { Calcium Cycling } \\
\text { Genes }\end{array}$} \\
\hline SERCA 1 & $\begin{array}{l}\text { Sarcoplasmic reticulum ATPase } \mathrm{Ca}^{2+} \text { dependent, } \\
\text { regulate } \mathrm{Ca}^{2+} \text { concentration in muscle; thyroid } \\
\text { hormone dependent }\end{array}$ & $\begin{array}{l}\text { Sense 5' TTCCCTTCAGCAACCTGCTCTC 3' } \\
\text { Anti-sense 5' AGTCAGCTAGTTGCCTTGTCCC 3' }\end{array}$ \\
\hline SERCA 2a & $\begin{array}{l}\text { Sarcoplasmic reticulum ATPase } \mathrm{Ca}^{2+} \text { dependent, } \\
\text { regulate } \mathrm{Ca}^{2+} \text { concentration in muscle; thyroid } \\
\text { hormone dependent }\end{array}$ & $\begin{array}{l}\text { Sense 5' AGTCATTAACAGTCCTAACTGTGG 3' } \\
\text { Anti-sense } 5^{\prime} \text { TGTGTTGCTAACAACGCACATGC 3' }\end{array}$ \\
\hline Sarcolipin & $\begin{array}{l}\text { Regulates SERCA; implicated in calcium slippage } \\
\text { and leak }\end{array}$ & $\begin{array}{l}\text { Sense } 5^{\prime} \text { TCCTGGAGTTCTCACCCAGACC } 3^{\prime} \\
\text { Anti-sense } 5^{\prime} \text { ACATGAGGAGCACAGTGATCAGG 3' }\end{array}$ \\
\hline $\begin{array}{l}\text { Candidate Genes by } \\
\text { Gene } \\
\text { Manipulation }\end{array}$ & & \\
\hline PGC-1 $\alpha$ & $\begin{array}{l}\text { Nuclear receptor coactivator linked to } \\
\text { mitochondrial biogenesis }\end{array}$ & $\begin{array}{l}\text { Sense } 5^{\prime} \text { TGAAAGGGCCAAGCAGAGAGAGAGG 3' } \\
\text { Anti-sense } 5^{\prime} \text { CGCAGATTTACGGTGCATTCCTCAA 3' }\end{array}$ \\
\hline Mitofusin 2 & $\begin{array}{l}\text { Participates in mitochondrial fusion, cell respiration } \\
\text { and mitochondrial proton leak }\end{array}$ & $\begin{array}{l}\text { Sense } 5^{\prime} \text { ACCTGAATCGGCACAGAGGAG } 3^{\prime} \\
\text { Anti-sense } 5^{\prime} \text { TGGAGTTGCATCGAGAAAAGAGC 3' }\end{array}$ \\
\hline IL6 & $\begin{array}{l}\text { Regulates body composition. IL6 -/- develop } \\
\text { obesity }\end{array}$ & $\begin{array}{l}\text { Sense 5' ACAGAGGATACCACCCACAACAG 3' } \\
\text { Anti-sense } 5^{\prime} \text { TGCATCATCGCTGTTCATACAATC 3' }\end{array}$ \\
\hline Nur77 & $\begin{array}{l}\text { Nuclear receptor superfamily; regulates lipolysis in } \\
\text { skeletal muscle cells; linked to } \beta \text {-adrenergic } \\
\text { receptor }\end{array}$ & $\begin{array}{l}\text { Sense 5' AGCTGTGGGCTCAGCTGTAG 3' } \\
\text { Anti-sense 5' TCTGAGTGGTGGAGCAGTCC 3' }\end{array}$ \\
\hline DGAT1 & $\begin{array}{l}\text { Involved in last step for triglycerides synthesis. } \\
\text { DGAT }-/- \text { are resistant to obesity }\end{array}$ & $\begin{array}{l}\text { Sense 5' ACAAAGACCGGCAGACCAGCG 3' } \\
\text { Anti-sense 5' ACGGTAATTGCTGAAACCGCTG 3' }\end{array}$ \\
\hline SCD1 & $\begin{array}{l}\text { First-step desaturation of fatty acids; SCD1 }-/- \text { are } \\
\text { resistant to obesity }\end{array}$ & $\begin{array}{l}\text { Sense } 5^{\prime} \text { TGG GAA AGT GAA GCG AGC AAC CG } 3^{\prime} \\
\text { Anti-sense } 5^{\prime} \text { AGA GGG GCA CCT TCT TCA TCT } \\
\text { TCT C } 3^{\prime}\end{array}$ \\
\hline Leptin & $\begin{array}{l}\text { Regulates body weight, in part via thermogenesis; } \\
\text { act in CNS and peripheral tissue; deficiency } \\
\text { causes obesity }\end{array}$ & $\begin{array}{l}\text { Sense 5' GTTGGACCTTAGCCCTGAATGC 3' } \\
\text { Anti-sense 5' GAGCCAAGGTTTCTTCCCTCAA 3' }\end{array}$ \\
\hline
\end{tabular}

rpm, the lower chloroform-containing layer was transferred into clean glass vials using pasteur pipettes. The extracts were redisolved in $75 \mu \mathrm{l}$ chloroform:methanol (2:1) and fractionated by thin-layer chromatography using thin layer plates coated with $0.25 \mathrm{~mm}$ silica gel. Plates were preconditioned by heating at $100^{\circ} \mathrm{C}$ for $2 \mathrm{~h}$ and were developed (20-30 min) using hexane:diethylether:acetic acid (60:40:1, vol.). The plates were allowed to dry in air, and the separated standard lipid fractions were sprayed with $10 \%$ copper sulfate in $8 \%$ phosphoric acid and visualized after heating for $20 \mathrm{~min}$ at $180^{\circ} \mathrm{C}$. Five lipid fractions, i.e., phospholipids (PL), mono- glycerides (MG), diglycerides (DG), free fatty acids (FFA), and triglycerides (TG) were scraped off the plates, and lipids were eluted in methanol (PL and MG fractions) or in chloroform (DG, FFA, and TG fractions). An internal standard (410 ng of nonadecanoic acid) was added to each fraction and treated with $10 \%$ BF3 in methanol as described by Morrison and Smith (38). The resulting mixtures of fatty acid methyl esters of the separated fractions were analyzed by gas chromatography/mass spectrometry (HP6890 coupled to an HP 5793 MSD; Agilent, Palo Alto, CA) using a capillary column (SP $2380 ; 30 \mathrm{~m} \times 0.25 \mathrm{~mm}, 0.2 \mu \mathrm{m}$ ) with the condi- 
tions described in the Supelco Bulletin 855B (Supelco, Bellefonte, PA). Fatty acid methyl esters were identified by reference to a mass spectral (electron impact) databank and by their retention times. Quantitation was performed by integration of the peaks in the total ion curve $(\mathrm{ms} / \mathrm{z} 50-800 \mathrm{amu})$. With the use of the quantitated values for palmitate (C16:0), palmitoleate $(\mathrm{C} 16: 1)$, stearate $(\mathrm{C} 18: 0)$, and oleate (C18:1), the desaturation index was determined by calculating the product:substrate ratio (16:1/16:0 and 18:1/18:0).

\section{Intramyocellular lipids}

The content of neutral lipids in skeletal muscle myocytes was determined using an oil red $\mathrm{O}(\mathrm{ORO})$ stain, as described by Russell et al. (39). In brief, tibialis anterior muscle sections were incubated in formalin for $10 \mathrm{~min}$ and washed $3 \times 30 \mathrm{~s}$ in deionized water before being stained for $7 \mathrm{~min}$. with the ORO solution. After being washed again for $3 \times 30 \mathrm{~s}$, the sections were counterstained with Harris's hematoxylin for 4 min and then rinsed under running tap water for $3 \mathrm{~min}$. The sections were covered with a coverslip and viewed using a Zeiss Axiophot I microscope mounted with an Axiocam color CCD camera. The intramyocellular neutral lipids were quantified using the Zeiss KS400 V3.0 program. Approximately $420 \pm 160$ fibers were scanned per muscle.

\section{Determination of energy balance and body composition}

Energy balance measurements were conducted during refeeding, as described previously $(10,12)$, by the comparative carcass technique over periods during which ME intake was monitored continuously. Energy expenditure was determined as the difference between energy gain and ME intake. After the animals were killed by decapitation, the skull, thorax, and abdominal cavity were incised and the gut cleaned of undigested food. The whole carcasses were dried to a constant weight in an oven maintained at $70^{\circ} \mathrm{C}$ and were subsequently homogenized. Triplicate samples of the homogenized carcass were analyzed for energy content by bomb calorimetry and for fat content by the Soxhlet extraction method, as described previously $(10,12)$. Body protein was determined from a general formula relating energy derived from fat, total energy value of the carcass, and energy derived from protein (10); the caloric values for body fat and protein were taken as 38.6 and $22.7 \mathrm{~kJ} / \mathrm{g}$, respectively.

\section{Blood hormone assay and urinary catecholamines}

On the day of blood collection, food was removed early in the morning (8:00 a.m.), and 6-7 h later, i.e., in the postabsorptive phase, blood obtained by decapitation was centrifuged and the plasma frozen and stored at $-20^{\circ} \mathrm{C}$ for later assays of hormones. Plasma leptin and thyroid hormones were measured using RIA kits (Linco, St. Charles, MD). Urinary catecholamines were assayed from urine collected from rats housed singly in customized metabolic cages equipped with a grid floor and a fiberglass funnel for urine collection; a special separator (Lab Products, Maywood, NJ) allowed automatic separation of urine and feces. The urine was collected in presence of 1-2 $\mathrm{ml}$ of $2 \mathrm{~N} \mathrm{HCL}$, and samples were stored at $-20^{\circ} \mathrm{C}$ until assayed for catecholamines using liquid chromatography with electrochemical detection.

\section{Data analysis and statistics}

All data are means \pm sE. The data were analyzed by MannWhitney nonparametric test (which makes no assumption about the normal distribution of data), and $P$ values $<0.05$ were considered significant. In cases of $P$ values $>0.05$ but $<0.1$ (i.e., not far from achieving statistical significance with the Mann-Whitney test), the data were also analyzed by Students $t$ test, a parametric test that assumes normal distribution and $P$ values $<0.05$ were considered significant. The statistical treatment of data was performed using the computer software STATISTIK, version 4.0 (Analytical Software, St. Paul, MN).

\section{RESULTS}

\section{Gene search relevant to suppressed thermogenesis}

In the search for skeletal muscle genes the altered expression of which at the end of semistarvation (RF-0) would still persist in the same direction at 1 wk of refeeding (RF-7), the application of mRNA differential display, followed by cDNA microarray analysis, did not reveal any gene the expression of which was altered by $>50 \%$ at both RF-0 and RF-7 (Supplementary Table S1). Furthermore, among several "structural" genes and one "unknown" gene the expressions of which tended to be altered in the same direction by $\approx 25 \%$ at these two time points (Supplementary Table S1), none could be confirmed by quantitative RT-PCR analysis (Table 2) whether in the tibialis anterior (a fast-twitch oxidative-glycolytic) muscle or in the soleus (a slowtwitch oxidative) muscle, except maternal expressed gene 3 (MEG3), which is also referred to as gene trapped locus 2 (GTL2), an untranslated RNA the specific function of which is unknown (40). The application of RT-PCR analysis to screen "literature" candidate genes implicated as effectors of thermogenesis (Table 1) also indicated that none of them showed statistically significant altered expression at RF-0, which persisted in the same direction at RF-7 in both tibialis anterior and soleus muscles, with the exception of SCD1. As indicated in Table 2, the mRNA levels of SCD1 in muscles from refed animals were significantly higher (by 2- to 4-fold) than in the respective controls both at RF-0 and at RF-7 and both in the tibialis anterior muscle and in the soleus muscle.

\section{Skeletal muscle specificity in SCD1 up-regulation}

To investigate whether this persistent up-regulation of muscle SCD1 gene expression at RF-0 and RF-7 is specific to skeletal muscle or also occurs in other tissues/organs where SCD1 is generally highly expressed, we also measured SCD1 mRNA levels in other muscles as well as in liver and white adipose tissues harvested from the same animals in the above study. The data presented in Fig. 2 indicate that unlike in skeletal muscle, SCD1 mRNA levels in liver were markedly lower than controls at RF-0 and did not exceed those of controls at RF-7, a pattern of SCD1 expression that was also found in the retroperitoneal adipose tissue, though not in the epididymal adipose tissue in which SCD1 mRNA levels were unaltered both during semistarvation and during refeeding. Thus, the upregulation of SCD1 gene expression is specific for 


\begin{tabular}{|c|c|c|c|c|}
\hline \multirow[b]{2}{*}{ Category/Gene Name } & \multicolumn{2}{|c|}{ Tibialis Anterior } & \multicolumn{2}{|c|}{ Soleus } \\
\hline & $\begin{array}{c}\text { Semistarvation } \\
\mathrm{R}_{0} / \mathrm{C}_{0}\end{array}$ & $\begin{array}{c}\text { Refeeding } \\
\mathrm{R}_{7} / \mathrm{C}_{7}\end{array}$ & $\begin{array}{c}\text { Semistarvation } \\
\mathrm{R}_{0} / \mathrm{C}_{0}\end{array}$ & $\begin{array}{c}\text { Refeeding } \\
\mathrm{R}_{7} / \mathrm{C}_{7}\end{array}$ \\
\hline \multicolumn{5}{|c|}{ Candidate Genes from Differential Display } \\
\hline MLC2 & $1.31 \pm 0.06$ & $0.93 \pm 0.06$ & $0.37 \pm 0.08^{*}$ & $0.89 \pm 0.26$ \\
\hline $\mathrm{MLC1} / 3$ & $0.91 \pm 0.33$ & $0.56 \pm 0.13$ & $0.35 \pm 0.07 *$ & $1.01 \pm 0.38$ \\
\hline MHC IIX/D & $1.63 \pm 0.22 *$ & $1.15 \pm 0.18$ & $1.28 \pm 0.81$ & $1.67 \pm 0.87$ \\
\hline MHC IIB & $1.09 \pm 0.14$ & $1.01 \pm 0.16$ & $0.32 \pm 0.09 *$ & $0.80 \pm 0.27$ \\
\hline Troponin $\mathrm{C}$ & $1.12 \pm 0.11$ & $1.05 \pm 0.11$ & $0.37 \pm 0.12 * *$ & $0.62 \pm 0.14$ \\
\hline Actin $\beta$ & $0.85 \pm 0.16$ & $0.76 \pm 0.08$ & $1.16 \pm 0.25$ & $0.76 \pm 0.20$ \\
\hline ColA1 & $0.54 \pm 0.10 *$ & $0.70 \pm 0.13$ & $4.95 \pm 1.48^{*}$ & $1.11 \pm 0.33$ \\
\hline MEG3 / GTL2 & $0.36 \pm 0.06 * *$ & $0.35 \pm 0.05^{* *}$ & $0.41 \pm 0.11^{*}$ & $0.28 \pm 0.06^{*}$ \\
\hline \multicolumn{5}{|c|}{ Calcium Cycling Genes } \\
\hline SERCA 1 & $2.21 \pm 0.53 *$ & $0.80 \pm 0.22$ & $0.73 \pm 0.12$ & $0.62 \pm 0.19$ \\
\hline SERCA 2a & $1.24 \pm 0.44$ & $0.52 \pm 0.20^{*}$ & ND & ND \\
\hline Sarcolipin & $0.55 \pm 0.16^{*}$ & $0.33 \pm 0.07 *$ & $3.48 \pm 0.89 *$ & $1.55 \pm 0.48^{*}$ \\
\hline \multicolumn{5}{|c|}{ Candidate Genes by Gene Manipulation } \\
\hline PGC-1 $\alpha$ & $0.67 \pm 0.07 *$ & $1.03 \pm 0.14$ & $1.25 \pm 0.27$ & $1.30 \pm 0.32$ \\
\hline Mitofusin 2 & $1.50 \pm 0.15$ & $1.35 \pm 0.28$ & $1.28 \pm 0.11$ & $1.07 \pm 0.10$ \\
\hline IL6 & $0.60 \pm 0.09$ & $0.96 \pm 0.29$ & $10.7 \pm 3.8^{* *}$ & $1.65 \pm 0.41$ \\
\hline Nur77 & $3.37 \pm 0.94 *$ & $0.44 \pm 0.07$ & $2.44 \pm 0.52$ & $0.55 \pm 0.12$ \\
\hline DGAT1 & $0.64 \pm 0.18$ & $0.81 \pm 0.14$ & $1.07 * \pm 0.19$ & $1.97 \pm 0.67$ \\
\hline SCD1 & $3.06 \pm 1.01 * *$ & $3.58 \pm 0.48^{* *}$ & $3.40 \pm 1.39 *$ & $2.49 \pm 0.38^{* *}$ \\
\hline Leptin & $0.56 \pm 0.10 *$ & $1.01 \pm 0.08$ & $0.91 \pm 0.21$ & $1.59 \pm 0.27$ \\
\hline
\end{tabular}

Data are provided as fold change compared with respective controls during semistarvation or during refeeding, and are given in arbitrary units (mean set to 1.0 ); ND $=$ not detectable; $* P<0.05 ; * * P<0.01$

skeletal muscle, since it is not observed in liver and white adipose tissue. Subsequent studies described below concentrate on the tibialis anterior muscle, since the fiber composition of this fast-twitch oxidative-glycolytic muscle reflects that observed for the bulk of skeletal muscle mass in the rat (41).

\section{Muscle SCD1 gene up-regulation and hormonal profile}

In a study designed to investigate the kinetics of altered SCD1 gene expression during 15 days of refeeding together with that of hormones known to stimulate skeletal muscle thermogenesis and to repress SCD1, namely leptin $(42,43)$, thyroid hormones $(23,43)$, and possibly also catecholamines (16), whose second messenger cAMP has been implicated in SCD1 repression (43), we assessed the following: 1) the mRNA levels of SCD1 in the muscle harvested from refed and control animals killed on the last day of semistarvation (i.e., on day 0 of refeeding) and on day 5, 10, and 15 of refeeding; 2) the plasma concentrations of leptin and the thyroid hormones (T3 and T4) at these same time
Figure 2. Muscle-specific increases in mRNA levels of SCD1 (normalized to that of cyclophilin) after 2 wk of semistarvation in food-restricted (R-0) and control (C-0) animals, as well as after $1 \mathrm{wk}$ of controled refeeding in refed (R-7) and control (C-7) animals. All values are means and SE $(n=6)$; * $P<0.05$; ** $P<0.01$.
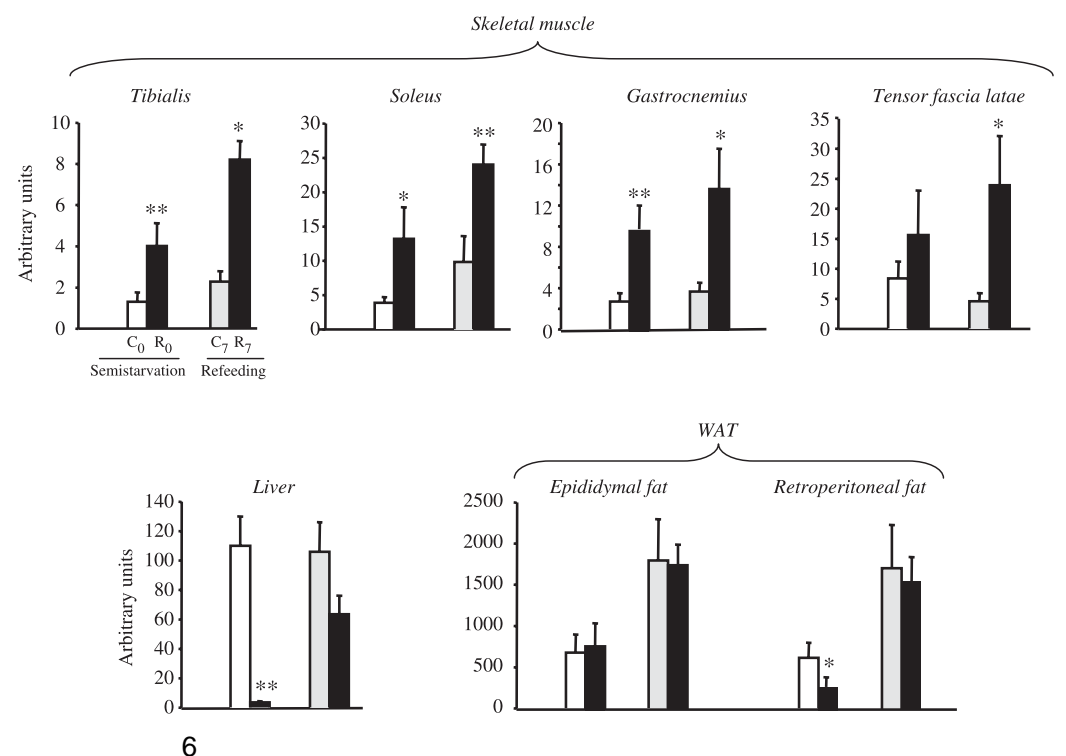

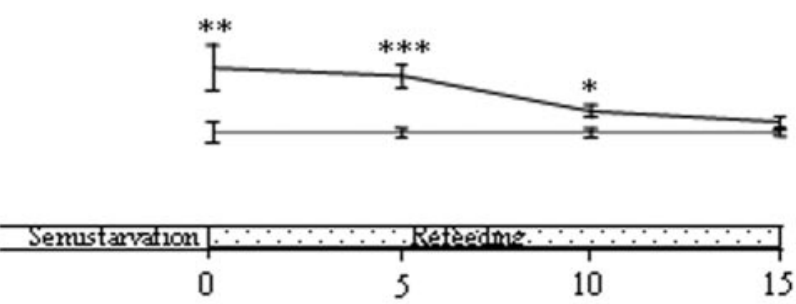

B
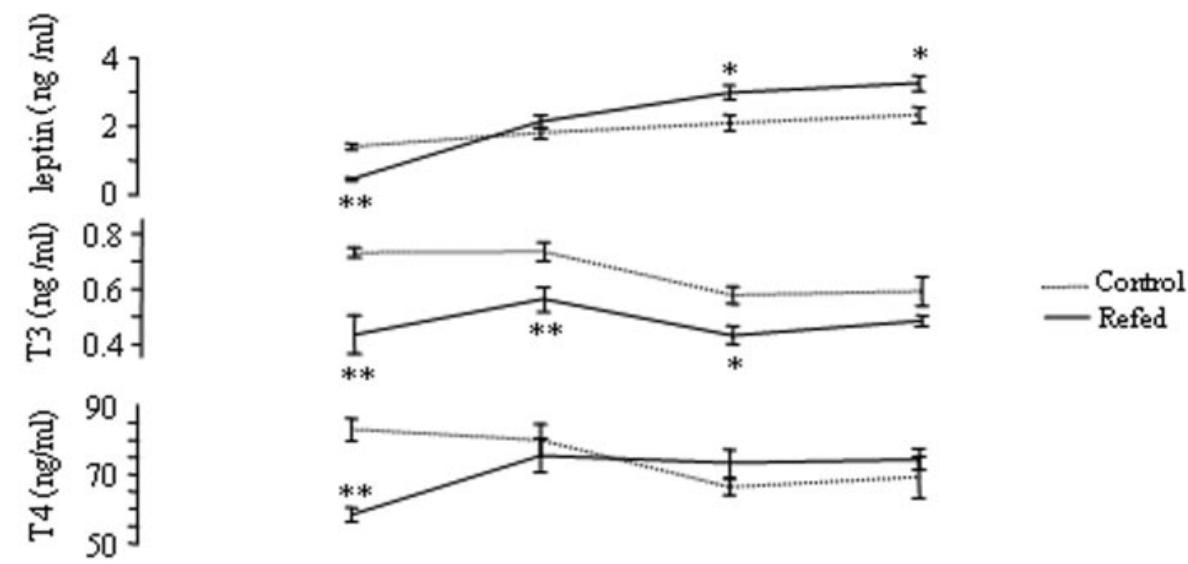

C
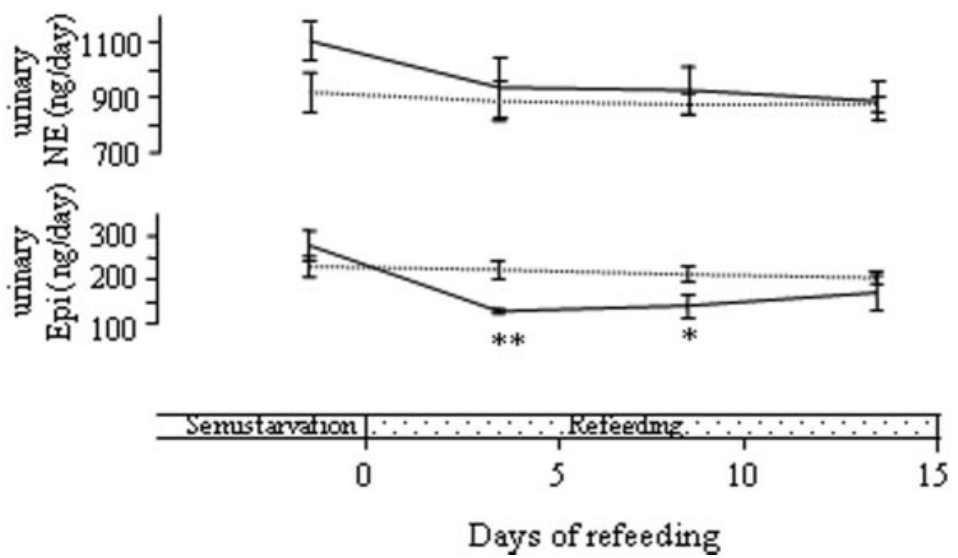

......... Control

- Refed

Figure 3. Pattern of mRNA levels of SCD1 (normalized to that of cyclophilin) in tibialis anterior muscle $(A)$, that of plasma leptin and thyroid hormones $(B)$, and that of urinary catecholamines $(C)$ at end of semistarvation and during course of refeeding. All values are means and SE $(n=6-8) ; * P<0.05$; $* * P<0.01 ; * * * P<0.001$. points; and 3) in a parallel experiment of similar design, urinary excretion rates of the two main catecholamines (epinephrine and norepinephrine) were measured from urine collected from each rat during days 12-14 of semistarvation and during days 3-5, 7-9, and 10-12 of refeeding. The results on the kinetics of SCD1 gene expression in skeletal muscle shown in Fig. $\mathbf{3 A}$ indicate that SCD1 mRNA levels were significantly higher relative to controls at RF-0 and RF-5 (by $\approx 3$ fold) and remained higher than controls ( $<2$-fold) until day 15. The difference between refed and controls was still statistically significant on day 10 but not on day 15. The data on plasma hormones shown in Fig. $3 B$ indicate a marked reduction in plasma leptin, T3, and $\mathrm{T} 4$ at the end of semistarvation (RF-0). However, whereas plasma leptin and plasma T4 were no longer below control levels from day 5 of refeeding onwards, plasma T3, by contrast, remained lower than in controls on day 5 as well as on day 10 of refeeding. The data on urinary catecholamines shown in Fig. $3 C$ indicate no significant differences between semistarved and control animals in urinary excretion rate of norepinephrine and epinephrine. During refeeding, however, whereas urinary NE excretion rate remained similar to that of controls, that of epinephrine was found to be lower than in controls, with the difference being significant during the periods of urine collection corresponding to the first 10 days of refeeding. Thus, whereas plasma leptin, T4, and T3 were significantly lower than in controls during semistarvation, only plasma T3 and the 
A $\Delta 9$ desaturation activity

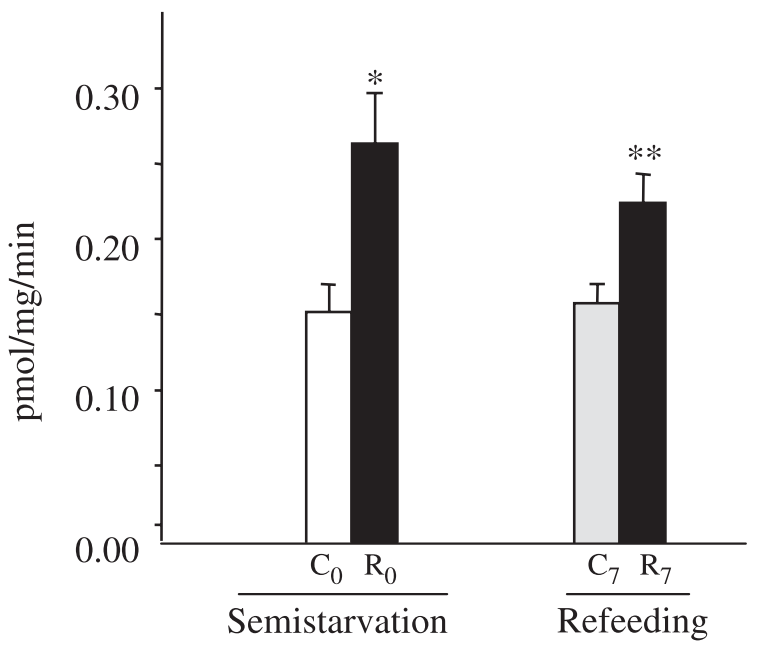

B Intramyocellular lipid content

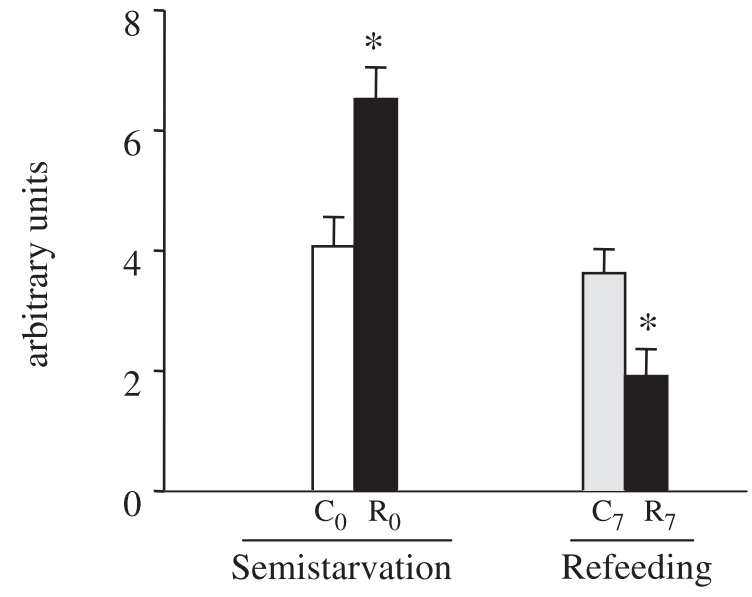

Figure 4. Microsomal $\Delta 9$ desaturase (SCD) activity $(A)$ and intramyocellular lipid content $(B)$ from skeletal muscle (tibialis anterior) at the end of 2 wk of semistarvation and after 1 wk of refeeding. All values are means and SE; $(n=6-8) ; * P<$ $0.05 ; * * P<0.01$.

urinary epinephrine excretion rate remained lower in refed animals than in controls during the phase of catch-up fat due to suppressed thermogenesis.

\section{Indices of muscle $\Delta 9$ desaturase activity, intramyocellular lipids, and fatty acid composition}

To determine potential effects of an elevated muscle SCD1 gene expression on fatty acid $\Delta 9$ desaturation and lipid composition, we assessed in the tibialis anterior muscle of animals at the end of the semistarvation and after $1 \mathrm{wk}$ of refeeding, i.e., at time-points RF-0 and RF-7, the following parameters 1) microsomal $\Delta 9$ desaturase (SCD) activity and intramyocellular lipid content, and 2) fatty acid composition and $\Delta 9$ desaturation index $(16: 1 / 16: 0$ and 18:1/18:0) of muscle lipid fractions.

The data on muscle SCD activity presented in Fig. $\mathbf{4 A}$ indicate that, in parallel to the elevated SCD1 mRNA levels, the enzyme activity of SCD is significantly elevated at the end of semistarvation $(+72 \%, P<0.02)$ and remains higher on day $7(+44 \%, P<0.01)$ of refeeding. The data on intramyocellular lipid content, presented in Fig. $4 B$ indicate that it is increased at the end of semistarvation $(+60 \%, P<0.5)$ but not on day 7 of refeeding when it was actually lower in muscle from refed animals than in controls $(50 \%, P<0.05)$.

The data in relation to monounsaturation by SCD1, as well as the ratio of polyunsaturated to saturated fatty acids (PUFA:SFA), are presented in Fig. 5 for semistarvation and in Fig. 6 for refeeding for the various lipid fractions: PL, MG, DG, and TG fractions; the data for fatty acid composition of the FFA fraction are not presented, as these were below the level of correct quantitation. The data on muscle fatty acid composition during semistarvation (Fig. 5) indicate that, compared with controls, the TG fraction of muscle from semistarved rats shows a significantly higher ratio of 18:1/18:0, as well as in the relative percentage of C18:1 fatty acids by $\approx 2$-fold $(P<0.01)$. Furthermore, the relative percentage of C16:1 is significantly higher in the DG fraction $(+30 \%, P<0.05)$, while that of C18:1 is significantly higher in the MG fraction $(+13 \%$, $P<0.05)$. In the PL fraction, in contrast, the ratio of $16: 1 / 16: 0$, as well as the relative percentages of C16:1 and C18:1, is significantly lower during semistarvation. These changes in the PL fraction of muscle from semistarved rats are associated with a significantly higher ratio of polyunsaturated to saturated fatty acids, i.e., a higher PUFA:SFA ratio $(P<0.05)$.

During refeeding, in contrast, the PUFA:SFA ratio in the PL fraction, as well as in the MG fraction, is significantly lower in muscles from refed animals than in controls, and this is associated with a significantly higher $\Delta 9$ desaturation index and relative proportion of monounsaturates than in controls (Fig. 6). In the muscle from refed animals, the PL fraction also shows a higher ratio of 18:1/18:0 $(+50 \%, P<0.01)$ and a higher relative percentage of C18:1 fatty acids $(+15 \%$, $P=0.05$ ), while the MG fraction shows a higher ratio of 16:1/16:0 $(+64 \%, P<0.01)$, a higher percentage of C16:1 fatty acids $(+72 \%, P<0.01)$, and a tendency for $18: 1 / 18: 0$ ratio and for $18: 1$ to be higher than in controls. Furthermore, although the ratio of 18:1/18:0 was not different in the DG fraction, the percentage of C18:1 fatty acid in this fraction was also found to be significantly higher in muscle from refed than from control animals $(+14 \%, P<0.05)$. Thus, our findings of an elevated gene expression of SCD1 (an enzyme that catalyzes the synthesis of MUFA) during both semistarvation and refeeding can indeed be associated with increased indices of $\Delta 9$ desaturation and/or content of the products of SCD1 (16:1 and/or 18:1) in several muscle lipid fractions.

\section{DISCUSSION}

In its capacity as the rate-limiting enzyme for de novo synthesis of MUFA, SCD1 catalyzes the introduction of 


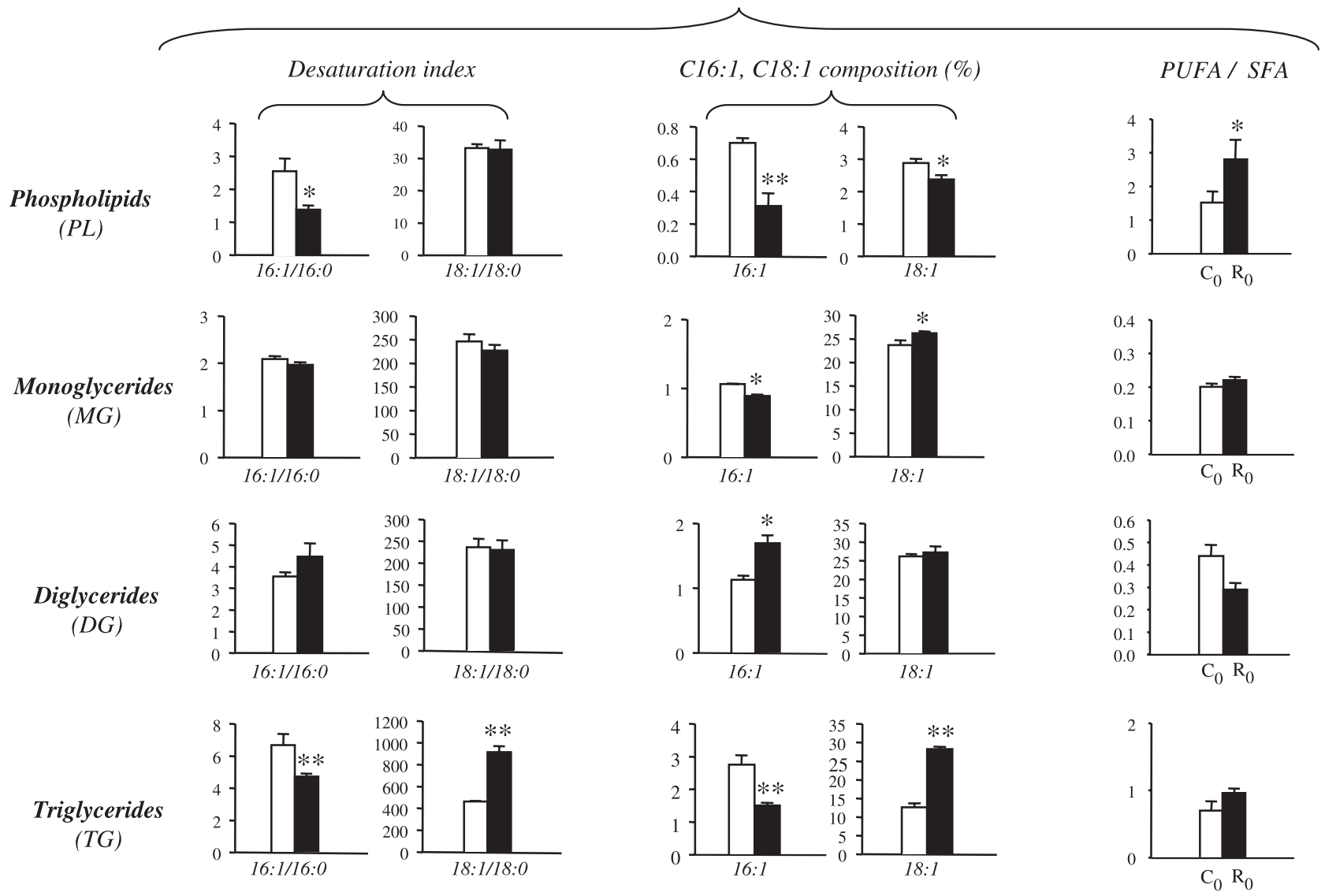

Figure 5. SCD1 desaturation index (16:1/16:0 and 18:1:18:0), relative content in monounsaturated fatty acids (C16:1, C18:1 composition), and ratio of polyunsaturated to saturated fatty acids (PUFA/SFA) in various lipid fractions of tibialis anterior muscle harvested after $2 \mathrm{wk}$ of semistarvation. All values are means and $\mathrm{SE}(n=6) ; * P<0.05 ; * * P<0.01$.

a double-bond at the $\Delta 9$ position of SFA, preferring palmitoyl-CoA (C16:0) and stearoyl-CoA (C18:0) as substrates, and producing palmitoleolyl-CoA (C16:1) and oleoyl-CoA (C18:1), respectively. These SCD1-derived MUFA, as opposed to those derived directly from dietary sources, are substrates for the synthesis of a variety of lipids (including phospholipids, cholesterol esters, wax esters, triacylglycerol, and alkyldiacylglycerols) that subserve a wide range of cellular and metabolic functions (44). As this study was in progress, a role for SCD1 as a negative modulator of thermogenesis was proposed based on investigations indicating that disruption of the SCD1 gene in mice results in markedly higher energy expenditure, which renders the animals resistant to obesity $(30,31,45)$. The studies presented here in a rat model of semistarvation-refeeding suggest that SCD1 in skeletal muscle may be an important control point in the effector system of the adiposespecific suppression of thermogenesis. First, the gene expression of SCD1, which is elevated in skeletal muscle after $2 \mathrm{wk}$ of semistarvation, remains elevated in parallel to the phase of suppressed thermogenesis that favors catch-up fat, which lasts for at least 10 days after the onset of refeeding. Second, these elevations in the SCD1 transcript in skeletal muscle are associated with elevations in SCD enzyme activity as well as in the relative content of the SCD1-derived monounsaturates (C16:1 and/or C18:1) in several lipid fractions extracted from skeletal muscle. Third, these elevations in SCD1 transcript and in indices of elevated SCD1 activity in skeletal muscle are inversely associated with levels of hormones known for their stimulatory effects on thermogenesis in skeletal muscle as well as for their potentially repressive effects on SCD1 expression. Taken together, these data underscore a role for skeletal muscle SCD1 up-regulation in the neurohormonal effector system that suppresses thermogenesis in favor of catch-up fat during weight recovery.

\section{Gene search}

The attribution to SCD1 of such a role in adaptive thermogenesis derives from the screening and validation, by quantitative RT-PCR, of three sets of candidate genes for an expression profile of persistent up-regulation or persistent down-regulation in skeletal muscle during early refeeding after semistarvation, namely 1 ) those genes identified for showing this pattern of expression by the technique of differential display followed by microarray analysis, notably genes that code for muscle-specific proteins related to structure/ 


\section{Refeeding}

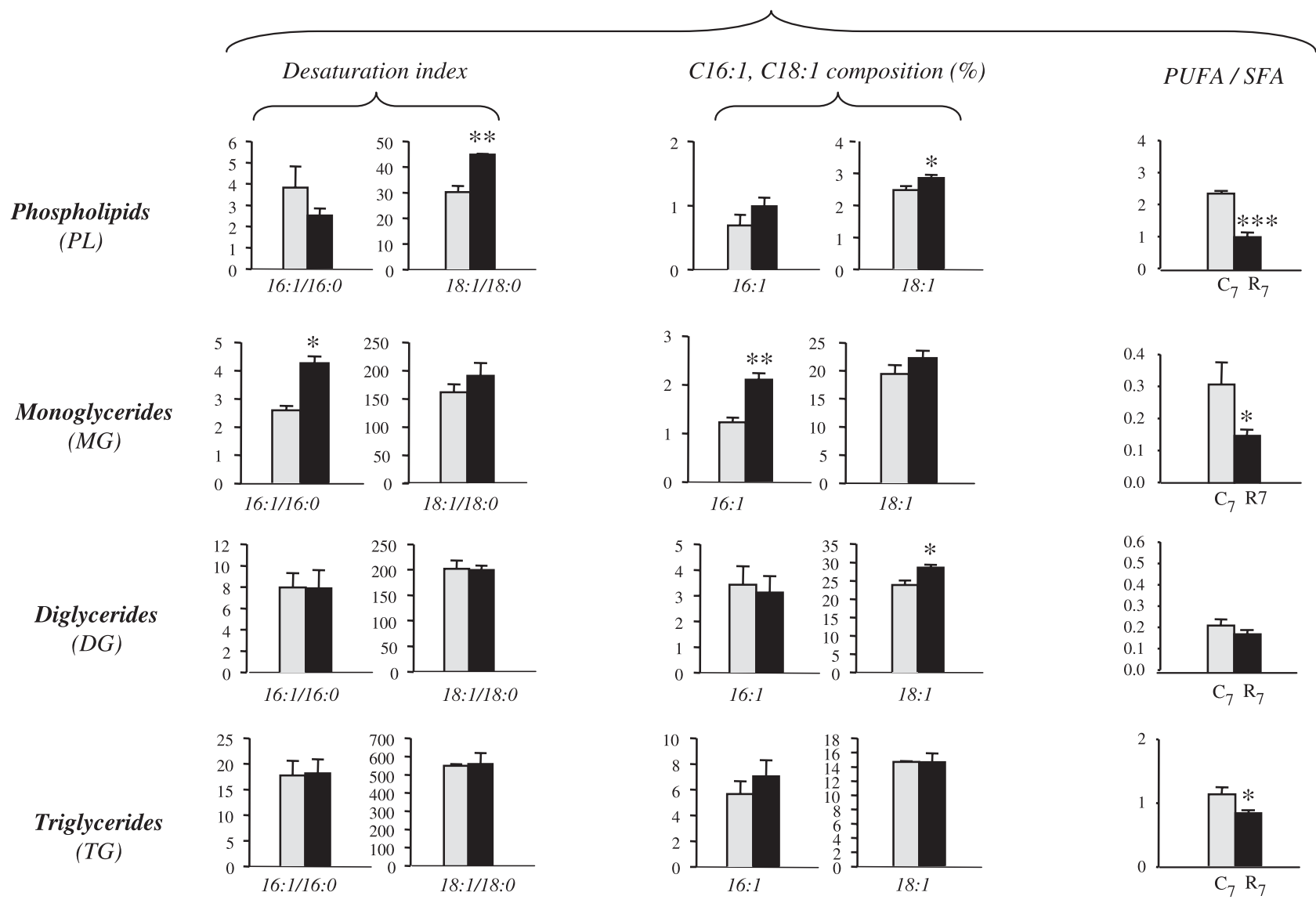

Figure 6. SCD1 desaturation index (16:1/16:0 and 18:1:18:0), relative content in monounsaturated fatty acids (C16:1, C18:1 composition), and ratio of polyunsaturated to saturated fatty acids (PUFA/SFA) in various lipid fractions of tibialis anterior muscle harvested after $1 \mathrm{wk}$ of refeeding. All values are means and $\mathrm{SE}(n=6) ; * P<0.05 ; * * P<0.01 ; * * * P<0.001$.

contraction (myosins and collagen) and MEG3/GTL2, an untranslated gene; 2) genes that are involved in calcium cycling (SERCA1, SERCA 2a, and sarcolipin), which are known to be regulated by thyroid hormones and possibly by catecholamines, and selected on the basis of literature findings that the reduction of circulating T3 concentrations during food restriction persists during refeeding in parallel to the recovery of weight (7); and 3) genes the deletion or overexpression of which, by gene manipulation technology in muscle cell systems or in generating transgenic mice, have been reported to result either in altered thermogenesis (PGC-1 $\alpha$, mitofusin2, IL6, DGAT1, and SCD1) or in an altered gene profile that is consistent with $\beta$-adrenergic control of thermogenesis (Nur77).

In the overall analysis of these data, SCD1 and MEG3/GTL2 were the only transcripts that showed the pattern of expression that consistently correlated with a persistent suppression of thermogenesis directed at catch-up fat during refeeding after semistarvation. The SCD1 transcript showed a robust elevation in mRNA levels of 3- to 4-fold relative to controls, both after $2 \mathrm{wk}$ of semistarvation and after 1 wk of refeeding, whereas the MEG3/GTL2 transcript showed a down-regulation (by $\approx 2$-fold) during semistarvation and refeeding.
However, since MEG is an untranslated gene the specific function of which is unknown (40), SCD1 is the only translated gene among those screened the pattern of expression of which was consistently found to correlate with the adipose-specific control of thermogenesis.

\section{Organ/tissue specificity}

This pattern of SCD1 gene regulation is skeletal muscle specific. In contrast to skeletal muscle where the SCD1 transcript is persistently up-regulated during the first 10 days of refeeding after semistarvation, it is either downregulated or unaltered in liver and in white adipose tissue during semistarvation and refeeding. This differential tissue regulation of SCD1 expression also suggests that the observed elevation in the SCD1 transcript in skeletal muscle is unlikely to have resulted from contaminations with adipocytes. Furthermore, our data indicating that 1) the gene expression of a classic adipocyte marker like leptin (which is expressed at very low levels in muscle) was not altered in skeletal muscle in response to semistarvation and refeeding (Table 2); and that 2) histological staining of neutral lipids of muscle sections with ORO did not reveal staining in areas other than in myocytes provide further evidence 
that excludes adipocyte contaminations as a contributing factor to the observed up-regulation of SCD1 in our skeletal muscle samples.

\section{Indices of SCD1 activity}

The functional relevance of these elevations in the SCD1 transcript to skeletal muscle lipid metabolism during semistarvation and refeeding is underlined by the results of subsequent analysis of microsomal and lipid fractions extracted from these muscles that indicate parallel elevations in several indices of SCD1 activity, namely 1) an increase in the enzyme activity of SCD in the microsomal fractions; 2) an increase in the relative content of SCD1-derived MUFA, palmitoleolylCoA (C16:1) and oleoyl-CoA (C18:1), in several lipid fractions; and 3) an increase in the SCD1 desaturation index that relates substrate and product in the reaction catalyzed by SCD1 and was calculated as the ratio of C18:1/C18:0 or C16:1/C16:0 in each lipid fraction using the quantitated values for palmitate (16:0), palmitoleate $(16: 1)$, stearate $(18: 0)$, and oleate $(18: 1)$.

These data reveal similarities, but also striking differences, in the changes in skeletal muscle lipid composition during semistarvation as opposed to those observed during refeeding. Whereas the elevations in muscle SCD1-desaturation index and/or in the relative proportion of the SCD1-derived-MUFA were found in the MG and DG fractions both in response to semistarvation and to refeeding, they were only observed in the TG fraction in response to semistarvation and only in the PL fraction in response to refeeding. The possibility thus arises that while both semistarvation and refeeding increased the relative content of SCD1-derived MUFA in the intermediates of lipid metabolism (i.e., MG and DG), semistarvation also increased the relative content of these monounsaturates in the storage lipids (i.e., TG) but not in the membrane lipids (i.e., PL), while refeeding also increased the relative content of these monounsaturates in the membrane lipids (i.e., PL) but not in the storage lipids. Indeed, the changes in fatty acid composition of the PL fraction in response to refeeding, i.e., increases in MUFA and in SFA and decreases in PUFA:SFA ratio, are exactly opposite to those observed during semistarvation, i.e., decreases in MUFA and SFA and an increase in PUFA:SFA ratio. Given the role attributed to the fatty acid composition of skeletal muscle PL and whole-body insulin sensitivity (46), these differential changes in fatty acid composition of PL are consistent with our previous demonstration, in this same semistarvation-refeeding rat model, that the shift from semistarvation to refeeding is accompanied by a shift from a state of increased insulin sensitivity during semistarvation to one of diminished insulin sensitivity and hyperinsulinemia during refeeding (12). The use of euglycemic-hyperinsulinemic clamp during refeeding has suggested that such suppression of thermogenesis directed at catch-up fat is accompanied by insulin resistance in skeletal muscle
(13), all of which precede the appearance of excess body fat and elevations in intramyocellular lipids.

These findings, together with the data reported here showing a persistent elevation of SCD1 and an increase in the proportion of MUFA in phospholipids and intermediate lipid fractions during refeeding therefore underscore potentially important link between SCD1 up-regulation in skeletal muscle and suppressed thermogenesis that spares glucose (Glc) from utilization in skeletal muscle for the purpose of catch-up fat. They also underscore a potentially important role for skeletal muscle SCD1 up-regulation in the mechanisms by which suppressed thermogenesis confers enhanced susceptibility to insulin resistance during catch-up growth or weight recovery in adults (47), a risk factor for later metabolic syndrome $(14,48)$.

\section{Linking muscle SCD1 up-regulation to suppressed thermogenesis}

The mechanisms by which these elevations in SCD1 activity and differential flux of SCD1-derived MUFA toward stored lipids (during semistarvation) or toward membrane lipids (during refeeding) might lead to suppressed thermogenesis in skeletal muscle are unknown. A common function of desaturases in organisms is to maintain the physical property of stored triglycerides and membrane lipids. One possibility therefore is that SCD1, by regulating the fatty acid composition of stored lipids and/or membrane phospholipids (49), induces modifications in lipid-signaling molecules and/or membrane fatty acid composition that might alter the activities of multiple regulatory enzymes and proteins that are involved in the cellular effector system that mediates thermogenesis. Of particular relevance in this context are the findings that the enhanced thermogenesis in mice lacking SCD1 can be associated with increases in the activities of skeletal muscle phosphatidylinositol-3 kinase (50) and AMPactivated protein kinase (51), two signaling pathways that have been shown to be required for hormonal stimulation of skeletal muscle thermogenesis possibly through their actions in orchestrating substrate cycling between de novo lipogenesis and lipid oxidation (5254). An alternative explanation is based on evidence that MUFA are much less potent than SFA as inhibitors of acetyl-CoA carboxylase $(55,56)$, the enzyme that catalyzes the synthesis of malonyl CoA, the immediate precursor for de novo synthesis of fatty acids. The possibility therefore arises that muscle SCD1 up-regulation, by increasing the conversion of de novo synthesized SFA to MUFA, would lead to diminished feedback inhibition of de novo synthesized fatty acids on the formation of their precursor substrate malonyl CoA, which is also an inhibitor of mitochondrial CPT1 shuttle system that controls import and oxidation of fatty acids (including SFA and MUFA) in mitochondria. Thus, as depicted in the schematic model presented in Fig. 7, by enhancing the conversion of the SFA products of de novo lipogenesis to MUFA, an elevated SCD1 


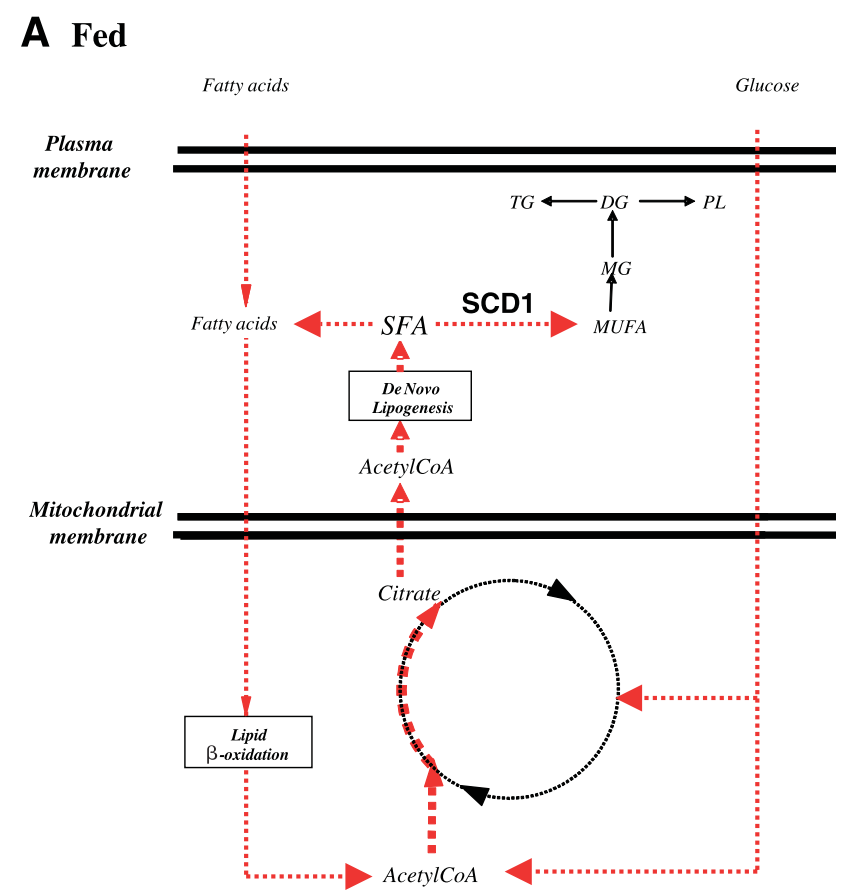

\section{B Semistarved/ Refed}

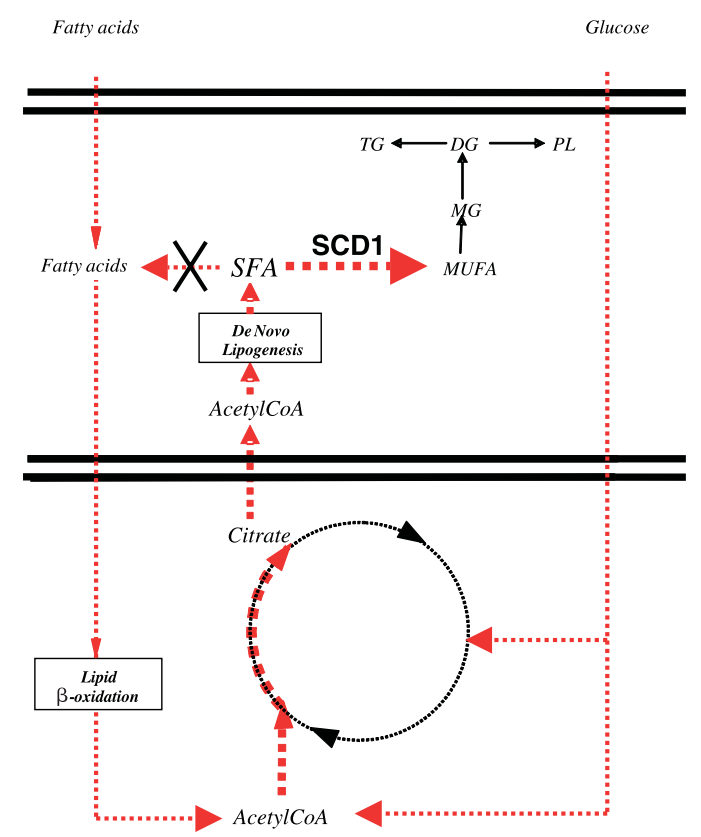

Figure 7. Model illustrating mechanisms by which an upregulation of SCD1 in skeletal muscle might lead to suppressed thermogenesis. In fed state $(A)$, repeated recycling of acetyl-CoA through flux of substrates across de novo lipogenesis followed by mitochondrial $\beta$-oxidation constitute an energy dissipating "substrate cycling" in skeletal muscle (52-54). During semistarvation and early refeeding $(B)$, an elevated SCD1 would, by enhancing the desaturation of de novo synthesized fatty acids, divert them away from pathways of mitochondrial $\beta$-oxidation and effectively shut down this thermogenic substrate cycling mechanism, thereby leading to energy conservation (see text for more details). would divert de novo synthesized SFA and its MUFA products away from pathways of lipid $\beta$-oxidation and effectively shut down this energy-dissipating substrate cycle, thereby leading to energy conservation. This model takes into account the differential effects of SCD1 up-regulation during semistarvation and refeeding, namely with the SCD1-derived MUFA being channeled, via the MG and DG intermediates of lipid metabolism, toward storage lipids (TG) during semistarvation, as opposed to being channeled toward membrane lipids (PL) during refeeding.

How these elevations in SCD1 gene transcription and activity are induced in skeletal muscle as a function of the size of fat stores during semistarvation and refeeding is also an important issue that remains to be addressed. It is, however, known that SCD1 gene transcription and/or SCD activity are repressed by hormones known to exert stimulatory effects on thermogenesis in skeletal muscle, namely leptin $(42,43)$ and thyroid hormones $(23,43)$ and possibly also catecholamines (16) whose second messenger cAMP has been implicated in SCD1 repression (43). Our findings here indicating that at least two of them are reduced during semistarvation (leptin, T3, and T4) and during the phase of suppressed thermogenesis that favors catch-up fat (T3 and epinephrine) are hence consistent with our proposal that skeletal muscle SCD1 is a key control point in the neurohormonal effector system of the adipose-specific control of thermogenesis.

In recent years, SCD1 has been proposed as a target for the treatment of obesity and the metabolic syndrome after the demonstrations that its disruption in mice, whether by natural mutation (30), by gene knockout technology (31), or by the use of specific antisense oligonucleotides (45), leads to enhanced thermogenesis, which confers resistance to obesity and its comorbidities. Together with a recent demonstration that SCD1 expression is up-regulated both in skeletal muscle and in primary skeletal myocytes from obese humans (57), our findings here implicating a role for skeletal muscle SCD1 up-regulation in the adaptive suppression of thermogenesis that regulates body fat stores have two major implications: 1) they underscore a physiological role of SCD1 in body weight and body composition regulation, and 2) they provide a physiological rationale for targeting skeletal muscle SCD1 or its lipid product moieties in the management of obesity as well as in counteracting the preferential catch-up fat phenotype that contributes to the pathophysiological consequences of rapid catch-up growth.

We thank Claudette Duret, Marie-Francoise Baeriswyl, and Jean-François Cajot for excellent technical support. This work was supported by the Swiss National Science Foundation (Grant No. 3200-B0-102156)

\section{REFERENCES}

1. Keys, A., Brozek, J., Henschel, A., Mickelson, O., and Taylor, H. L. (1950) The Biology of Human Starvation. University of Minnesota Press, Minneapolis, MN 
2. Dulloo, A. G., and Jacquet, J. (1998) Adaptive reduction in basal metabolic rate in response to food deprivation in human: a role for feedback signal from the fat stores. Am. J. Clin. Nutr. 68, 599-606

3. Weyer, C., Walford, R. L., Harper, I. T., Milner, M., MacCallum, T., Tataranni, P. A., and Ravussin, E. (2000) Energy metabolism after 2 y of energy restriction: the Biosphere 2 experiment. Am. J. Clin. Nutr. 72, 946-953

4. Dulloo, A. G., and Girardier, L. (1993) $24 \mathrm{~h}$ energy expenditure several months after weight loss in the underfed rat: evidence for a chronic increase in whole-body metabolic efficiency. Int. J. Obes. Relat. Metab. Disord. 17, 115-123

5. Boyle, P. C., Storlien, L. H., and Keesey, R. E. (1978) Increased efficiency of food utilization following weight loss. Physiol. Behav. 21, 261-264

6. Hill, J. O., Fried, S. K., and Digirolamo, M. (1984) Effects of fasting and restricted refeeding on utilization of ingested energy in rats. Am. J. Physiol. 247, R318-R327

7. Harris, R. B. S., and Martin, R. J. (1984) Recovery of body weight from below "Set Point" in mature female rats. J. Nutr. 114, $1143-1150$

8. MacLean, P. S., Higgins, J.A., Johnson, G. C., Fleming-Elder, B. K., Donahoo, W. T., Melanson, E. L., and Hill, J. O. (2004) Enhanced metabolic efficiency contributes to weight regain after weight loss in obesity-prone rats. Am. J. Physiol. 287, R1306-R1315

9. Evans, S. A., Messina, M. M., Knight, W. D., Parsons, A. D., and Overton, J. M. (2005) Long-Evans and Sprague-Dawley rats exhibit divergent responses to refeeding after caloric restriction. Am. J. Physiol. 288, R1468-R1476

10. Dulloo, A. G., and Girardier, L. (1990) Adaptive changes in energy expenditure during refeeding following low calorie intake: evidence for a specific metabolic component favouring fat storage. Am. J. Clin. Nutr. 52, 415-420

11. Dulloo, A. G., and Jacquet, J. (2001) An adipose-specific control of thermogenesis in body weight regulation. Int. J. Obes. Relat. Metab. Disord. 25, Suppl. 5, S22-S29

12. Crescenzo, R., Samec, S., Antic, V., Rohner-Jeanrenaud, F., Seydoux, J., Montani, J. P., and Dulloo, A. G. (2003) A role for suppressed thermogenesis favouring catch-up fat in the pathophysiology of catch-up growth. Diabetes 52, 1090-1097

13. Cettour-Rose, P., Samec, S., Russell, A. P., Summermatter, S. Mainieri, D., Carrillo-Theander, C., Montani, J. P., Seydoux, J., Rohner-Jeanrenaud, F., and Dulloo, A. G. (2005) Redistribution of glucose from skeletal muscle to adipose tissue during catch-up fat: a link between catch-up growth and later metabolic syndrome. Diabetes $\mathbf{5 4}, \mathbf{7 5 1 - 7 5 6}$

14. Dulloo, A. G., Jacquet, J., and Montani, J. P. (2002) Pathways from weight fluctuation to metabolic disease: focus on maladaptive thermogenesis during catch-up fat. Int. J. Obes. Relat. Metab. Disord. 26, Suppl. 2, S46-S57

15. Dulloo, A.G., Seydoux, J., and Girardier, L. (1995) Disssociation of enhanced efficiency of fat deposition during weight recovery from sympathetic control of thermogenesis. Am. J. Physiol. 269, R365-R369

16. Landsberg, L., Saville, M. E., and Young, J. B. (1984) Sympathoadrenal system and regulation of thermogenesis. Am. J. Physiol. 247, E181-E189

17. Dulloo, A. G., Young, J. B., and Landsberg, L. (1988) Sympathetic nervous system responses to cold exposure and diet in rat skeletal muscle. Am. J. Physiol. 255, E180-E188

18. Ma, S. W. Y ., and Foster, D. O. (1986) Starvation-induced changes in metabolic rate, blood flow, and regional energy expenditure in rats. Can. J. Physiol. Pharmacol. 64, 1252-1258

19. Boss, O., Samec, S., Kuhne, F., Bijlenga, P., AssimacopoulosJeannet, F., Seydoux, J., Giacobino, J. P., and Muzzin, P. (1998) Uncoupling protein-3 expression in rodent skeletal muscle is modulated by food intake but not by changes in environmental temperature. J. Biol. Chem. 273, 5-8

20. Samec, S., Seydoux, J., and Dulloo, A. G. (1998) Role of UCP homologues in skeletal muscle and brown adipose tissue: mediators of thermogenesis or regulators of lipids as fuel substrate? FASEB J. 12, 715-724

21. Harper, M. E., Dent, R. M., Bezaire, V., Antoniou, A., Gauthier, A., Monemdjou, S., and McPherson, R. (2001) UCP3 and its putative function: consistencies and controversies. Biochem. Soc. Trans. 29, 768-773
22. Crescenzo, R., Mainieri, D., Solinas, G., Montani, J. P., Seydoux, J., Liverini, G., Iossa, S., Dulloo, A. G, (2003) Skeletal muscle mitochondrial oxidative capacity and uncoupling protein 3 are differently influenced by semistarvation and refeeding. FEBS Lett. 544, 138-142

23. Simonides, W. S., Thelen, M. H., van der Linden, C. G., Muller, A., and van Hardeveld, C. (2001) Mechanism of thyroid-hormone regulated expression of the SERCA genes in skeletal muscle: implications for thermogenesis. Biosci. Rep. 21, 139-154

24. Smith, W. S., Broadbridge, R, East, J. M., and Lee, A. G. (2002) Sarcolipin uncouples hydrolysis of ATP from accumulation of $\mathrm{Ca} 2+$ by the Ca2+-ATPase of skeletal-muscle sarcoplasmic reticulum. Biochem. J. 361, 277-286

25. Puigserver, P., Wu, Z., Park, C. W., Graves, R., Wright, M., and Spiegelman, B. M. (1998) A cold-inducible coactivator of nuclear receptors linked to adaptive thermogenesis. Cell 92, 829839

26. Bach, D., Pich, S., Soriano, F. X., Vega, N., Baumgartner, B., Oriola, J., Daugaard, J. R., Lloberas, J., Camps, M., Zierath, J. R., et al. (2003) Mitofusin-2 determines mitochondrial network architecture and mitochondrial metabolism. A novel regulatory mechanism altered in obesity. J. Biol. Chem. 278, $17190-17197$

27. Wallenius, V., Wallenius, K., Ahren, B., Rudling, M., Carlsten, H., Dickson, S. L., Ohlsson, C., and Jansson, J. O. (2002) Interleukin-6-deficient mice develop mature-onset obesity. Nat. Med. 8, 75-79

28. Maxwell, M. A., Cleasby, M. E., Harding, A., Stark, A., Cooney, G. J., and Muscat, G. E. (2005) Nur77 regulates lipolysis in skeletal muscle cells. Evidence for cross-talk between the betaadrenergic and an orphan nuclear hormone receptor pathway. J. Biol. Chem. 280, 12573-12584

29. Smith, S. J., Cases, S., Jensen, D. R., Chen, H. C., Sande, E., Tow, B., Sanan, D. A., Raber, J., Eckel, R. H., and Farese, R. V., Jr. (2000) Obesity resistance and multiple mechanisms of triglyceride synthesis in mice lacking Dgat. Nat. Genet. 25, $87-90$

30. Cohen, P., Miyazaki, M., Socci, N. D., Hagge-Greenberg, A., Liedtke, W., Soukas, A. A., Sharma, R., Hudgins, L. C., Ntambi, J. M., and Friedman, J. M. (2002) Role for stearoyl-CoA desaturase-1 in leptin-mediated weight loss. Science 297, 240-243

31. Ntambi, J. M., Miyazaki, M., Stoehr, J. P., Lan, H., Kendziorski, C. M., Yandell, B. S., Song, Y., Cohen, P., Friedman, J. M., and Attie, A. D. (2002) Loss of stearoyl-CoA desaturase-1 function protects mice against adiposity. Proc. Natl. Acad. Sci. U. S. A. 99, 11482-11486

32. Zhang, Y., Proenca, R., Maffei, M., Barone, M., Leopold, L. and Friedman, J. M. (1994) Positional cloning of the mouse obese gene and its human homologue. Nature (London) $\mathbf{3 7 2}$, 425-432

33. Wang, J., Liu, R., Hawkins, M., Barzilai, N., and Rossetti, L. (1998) A nutrient-sensing pathway regulates leptin gene expression in muscle and fat. Nature 393, 684-688

34. Brenz Verca, M. S., Brenz Verca, S., Rusconi, S., and Dreyer, J. L. (1998) Modification of primer design facilitates the use of differential display. BioTechniques 24, 374-380

35. Chomczynski, P., and Sacchi, N. (1987) Single-step method of RNA isolation by acid guanidinium thiocyanate-phenol-chloroform extraction. Anal. Biochem. 162, 156-159

36. Houdali, B., Wahl, H .G., Kresi, M., Nguyen, V., Haap, M., Machicao, F., Ammon, H. P., Renn, W., Schleicher, E. D., and Haring, H. U. (2003) Glucose oversupply increases Delta9desaturase expression and its metabolites in rat skeletal muscle. Diabetologia 46, 203-212

37. Bligh, E. G., and Dyer, W. J. (1959) A rapid method of total lipid extraction and purification. Can. J. Biochem. Physiol. 37, 911-917

38. Morrison, W. R., and Smith, L. M. (1964) Preparation of fatty acid methyl esters and dimethylacetals from lipids with boron fluoride-methanol J. Lipid Res. 5, 600-608

39. Russell, A. P, Gastaldi, G., Bobbioni-Harsch, E., Arboit, P., Gobelet, C., Dériaz, O., Golay, A., Witztum, J. L., and Giacobino, J. P. (2003) Lipid peroxidation in skeletal muscle of obese as compared to endurance trained humans: a case of good vs. bad lipids? FEBS Letters. 551, 104-106

40. Wylie, A. A., Murphy, S. K., Orton, T. C., and Jirtle, R. L. (2000) Novel imprinted DLK1/GTL2 domain on human chromosome 
14 contains motifs that mimic those implicated in IGF2/H19 regulation. Genome Res. 10, 1711-1718

41. Ariano, M. A., Armstrong, R. B., and Edgerton, V. R. (1973) Hindlim muscle fiber populations of five mammals. J. Histochem. Cytochem. 21, 51-55

42. Dulloo, A. G., Stock, M. J., Solinas, G., Boss, O., Montani, J. P., and Seydoux, J. (2002) Leptin directly stimulates thermogenesis in skeletal muscle. FEBS Letters 515, 109-113

43. Ntambi, J. M., Miyazaki, M., and Dobryn, A. (2004) Regulation of stearoyl-CoA desaturase expression. Lipids 39, 1061-1065

44. Nakamura, M. T., and Nara, T. Y. (2004) Structure, function, and dietary regulation of delta6, delta5, and delta9 desaturases. Annu. Rev. Nutr. 24, 345-376

45. Jiang, G., Li, Z., Liu, F., Ellsworth, K., Dallas-Yang, Q., Wu, M., Ronan, J., Esau, C., Murphy, C., Szalkowski, D., et al. (2005) Prevention of obesity in mice by antisense oligonucleotide inhibitors of stearoyl-CoA desaturase-1. J. Clin. Invest. 115, $1030-1038$

46. Borkman, M., Storlien, L. H., Pan, D. A., Jenkins, A. B., Chisholm, D. J., and Campbell, L. V. (1993) The relation between insulin sensitivity and the fatty-acid composition of skeletal-muscle phospholipids. N. Engl. J. Med. 328, 238-244

47. Dulloo, A. G. (2005) A role for suppressed skeletal muscle thermogenesis in pathways from weight fluctuations to the insulin resistance syndrome. Acta Physiol. Scand. 184, 295-307

48. Ong, K. K., and Dunger, D. B. (2004) Birth weight, infant growth and insulin resistance. Eur. J. Endocrinol. 151, Suppl. 3, U131-U139

49. Enoch, H. G., Catala, A., and Strittmatter, P. (1976) Mechanism of rat liver microsomal stearyl-CoA desaturase. Studies of the substrate specificity, enzyme-substrate interactions, and the function of lipid. J. Biol. Chem. 251, 5095-5103

50. Rahman, S. M., Dobrzyn, A., Dobrzyn, P., Lee, S. H., Miyazaki, M., and Ntambi, J. M. (2003) Stearoyl-CoA desaturase 1 deficiency elevates insulin-signaling components and down-regulates protein-tyrosine phosphatase 1B in muscle. Proc. Natl. Acad. Sci. U. S. A. 100, 11110-11115
51. Dobrzyn, A., Dobrzyn, P., Lee, S.H., Miyazaki, M., Cohen, P., Asilmaz, E., Hardie, D. G., Friedman, J. M., and Ntambi, J. M. (2005) Stearoyl-CoA desaturase-1 deficiency reduces ceramide synthesis by down-regulating serine palmitoyltransferase and increasing beta-oxidation in skeletal muscle. Am. J. Physiol. Endocrinol Metab. 288, E599-E607

52. Solinas, G., Summermatter, S., Mainieri, D., Gubler, M., Pirola, L., Wymann, M. P., Rusconi, S., Montani, J. P., Seydoux, J., and Dulloo, A. G. (2004) The direct effect of leptin on skeletal muscle thermogenesis is mediated by substrate cycling between de novo lipogenesis and lipid oxidation. FEBS Lett. 577, 539-44

53. Solinas, G., Summermatter, S., Mainieri, D., Gubler, M., Montani, J. P., Seydoux, J., Smith, S. R., and Dulloo, A. G. (2006) Corticotropin-releasing hormone directly stimulates thermogenesis in skeletal muscle possibly through substrate cycling between de novo lipogenesis and lipid oxidation. Endocrinology $147,31-38$

54. Dulloo, A. G., Gubler, M., Montani, J. P., Seydoux, J., and Solinas, G. (2004) Substrate cycling between de novo lipogenesis and lipid oxidation: a thermogenic mechanism against skeletal muscle lipotoxicity and glucolipotoxicity. Int. J. Obes. Relat. Metab. Disord. 28, Suppl. 4, S29-S37

55. Volpe, J. J., and Vagelos, P. R. (1976) Mechanisms and regulation of biosynthesis of saturated fatty acids. Physiol. Rev. 56, 339-417

56. Lunzer, M. A., Manning, J. A., and Ockner, R. K. (1977) Inhibition of rat liver acetyl coenzyme A carboxylase by long chain acyl CoA and fatty acid. Modulation by fatty acid-binding protein. J. Biol. Chem. 252, 5483-5487

57. Hulver, M. W., Berggren, J. R., Carper, M. J., Miyazaki, M., Ntambi, J. M., Hoffman, E P., Thyfault, J. P., Stevens, R., Dohm, G. L., Houmard, J. A., and Muoio, D. M. (2005) Elevated stearoyl-CoA desaturase-1 expression in skeletal muscle contributes to abnormal fatty acid partitioning in obese humans. Cell Metab. 2, 251-261 